\title{
Internal Fetal Heart Rate Monitoring
}

National Cancer Institute

\section{Source}

National Cancer Institute. Internal Fetal Heart Rate Monitoring. NCI Thesaurus. Code C114083.

A technique that utilizes a wire attached to the fetal scalp to monitor fetal heart rate. The wire detects fetal cardiac electrical activity to determine the baseline fetal heart rate and variability. 